\title{
Entre a décadence e a rangordnung: anotações sobre a crítica de Nietzsche à modernidade
}

Antonio Edmilson Paschoal

Professor de Filosofia na PUCPR

Resumo: Este artigo tem a finalidade de indicar alguns traços da crítica de Nietzsche à modernidade e apresentar 0 modo como ele estabelece sua tarefa em relação a ela e seu projeto filosófico a partir dela. Nesse sentido, cabe observar que Nietzsche reivindica uma diferença radical entre a modernidade e sua filosofia: enquanto a primeira é caracterizada como uma decadência (décadence), a segunda postularia uma espécie de hierarquia (Rangordnung). Tal oposição, contudo, não impede o filósofo de postular que seu projeto filosófico encontra raízes no seu tempo e tem por meta levar adiante certos propósitos e contradições internas da própria modernidade.

Palavras-chave: Nietzsche. Wagner. Modernidade. Décadence. Rangordnung.
Abstract: This article aims to point out some features of Nietzsche's critique of modernity and to present how he establishes his task against it and his philosophical project from it. In this sense, it should be noted that Nietzsche claims a radical difference between modernity and his own philosophy: while the first is characterized as a form of decadence (décadence), the second postulates some sort of hierarchy (Rangordnung). Such opposition, however, does not prevent Zarathustra's author to postulate that his philosophical project is rooted in his time and aims to carry out certain purposes and internal contradictions of modernity itself.

Keywords: Nietzsche. Wagner. Modernity. Décadence. Rangordnung.

1. NIETZSCHE, Sämtliche Werke, 1988. Kritische Studienausgabe. Herausgegeben von Giorgio Colli und Mazzino Montinari. Berlin/New York: Walter de Gruyter, 1988, vol. 12, p. 440. Para as citações de Nietzsche, no intuito de facilitar a localização dos textos nas suas diferentes edições, farei as citações 


\section{A polissemia do termo "modernidade" nos escritos de Nietzsche}

Se, por um lado, é plausível entender a obra de Nietzsche como um diagnóstico e uma crítica da modernidade, ${ }^{2}$ por outro, é pertinente afirmar que o termo "Modernität" possui diferentes contornos e nuances em seus escritos, mostrando-se, em alguns momentos, polissêmico $^{3}$ e, em outros, ambíguo. Por exemplo, quando ele se declara herdeiro e continuador da mesma modernidade que critica. ${ }^{4}$

Ao certo, a polissemia do termo se deve, em grande parte, à própria multiplicidade de fatores artísticos, culturais e políticos reu-

por meio da sigla já convencionada da obra e o número do aforismo ou a seção correspondente e, em seguida, acrescentarei o formato autor, data, volume e página da KSA. No caso dos fragmentos e anotações pessoais de Nietzsche, antes da citação no modelo autor-data, indicarei o ano do fragmento e o caderno, seguindo dessa forma o modelo já convencionado para essas citações. A presente citação, nesse formato é: Fragmento de 1887, $9[177]$.

2. Entre outros, Oswaldo Giacoia Junior analisa essa crítica de Nietzsche à modernidade em: GIACOIA JR., O. Esclarecimento (per) verso: Nietzsche à sombra da ilustração. In: Revista de Filosofia Aurora, v. 20, n. 27, p. 243-259, jul./dez. 2008a e também em: GIACOIA JR., O. Moralidade e Memória: Dramas do Destino da Alma. In: PASCHOAL, A. E. \& FREZZATTI JR., W. A. (Orgs.) 120 Anos de Para a Genealogia da Moral. Ijuí: Ed. Unijuí, p.187-241, 2008. Neste último, especialmente as ps. 27 e ss.

3. Conferir: KUHN, E. Cultur Civilisation, die Zweideutigkeit des "Modernen". In: Nietzsche-Studien, Berlim, n. 18, 1989, p. 600-626. É certo que o caráter polissêmico não se verifica apenas em relação à noção de modernidade em Nietzsche, mas também a outros conceitos, tais como os de ressentimento e de má consciência (PASCHOAL, A. E. Da polissemia dos conceitos "ressentimento" e "má consciência". Revista de Filosofia Aurora, Curitiba, v. 23, n. 32, jan./jun 2011a, p. 201-221), caracterizando-se mesmo como um traço marcante nos escritos do filósofo (SIEMENS, H. \& VAN TONGEREN, P. Introdução: o dicionário Nietzsche. In: Cadernos Nietzsche, São Paulo: n. 31, v. 02, 2012, p. 31-53).

4. A ideia de herdeiro encontra-se, por exemplo, na seção 4 do prefácio de Aurora. É interessante considerar, contudo, tendo em vista o mesmo livro de Aurora, o aforismo 542, no qual os "autênticos continuadores" são apresentados como os "autênticos opositores" (A 542 / NIETZSCHE, 1988, vol. 3, p. 311-312). 
nidos sob a alcunha de "modernidade", ou da "civilização" 5 que se configura a partir da Revolução Francesa. Em termos filosóficos, essa multiplicidade pode ser observada, por exemplo, tomando-se alguns dos nomes que compõem a modernidade pela qual Nietzsche se interessa. De fato, entre eles encontram-se desde os "filósofos da moda", como os "Leões de Berlin: Eugen Dühring e Eduard von Hartmann", ou um "filisteu da cultura", como David Strauss, ${ }^{7}$ até pensadores clássicos como Voltaire e Rousseau, relacionados à Revolução Francesa e em luta entre si. ${ }^{8}$ Também nesse registro e desempenhando um papel relevante nos escritos de Nietzsche, encontram-se os "trabalhadores filosóficos", como é o caso de Kant e Hegel, cuja tarefa consistiu em "estabelecer e colocar em fórmulas" corpos de valorações que se tornaram dominantes e foram apresentadas como "verdades" ${ }^{\prime \prime}$. Encontra-se, ainda nesse registro, para nos limitarmos aos exemplos mais mencionados por Nietzsche, o seu "mestre", Schopenhauer, cujo projeto de uma despotencialização da razão não teria significado um rompimento com conceitos básicos da modernidade como o de "eu"110, pois o seu "eu quero" teria o mesmo caráter de certeza imediata que o "eu penso" de Descartes possui. ${ }^{11}$

Com o conceito de "eu" e com a noção de sujeito, especialmente se considerarmos um "eu" capaz de deliberar por suas ações, um "sujeito livre" e imputável, tem-se um ponto de convergência para os diferentes nomes e pensamentos que se reúnem sob a alcunha nietzschiana de modernidade. Para o filósofo, a modernidade corresponderia a um desdobramento do cristianismo, da moral platônico-cristã. Isto porque a filosofia desenvolvida nela, com traços de uma independência da razão e de um questionamento sobre suas potencialidades, nada mais faria do que recolocar em cena os mesmos ideais cristãos, porém, em bases mais sólidas e notadamente mais "científicas". Como faz Kant, por exemplo, ao restabelecer o velho ideal em novas bases

\footnotetext{
5. Fragmento de 1887, 9[185] / NIETZSCHE, 1988, vol. 12, p. 449.

6. ABM 204 / NIETZSCHE, 1988, vol. 5, p. 131.

7. CE I 2 / NIETZSCHE, 1988, vol. 1, p. 171.

8. Fragmento de 1887, 9[185] / NIETZSCHE, F. 1988, vol. 12, p. 449.

9. ABM $211 /$ NIETZSCHE, 1988, vol. 5, p. 144.

10. ABM 19 / NIETZSCHE, 1988, vol. 5, p. 33.

11. ABM 16 / NIETZSCHE, 1988, vol. 5, p. 30.
} 
mais seguras ${ }^{12}$ e também Eugen Dühring, ao apresentar a mesma predisposição cristã de "sacralizar a vingança em nome da justiça", porém, com uma "nova nuance de equidade científica"13.

Considerada, pois, em relação aos períodos anteriores, à exceção da renascença, a modernidade seria o ápice de um processo de decadência que se instala na cultura ocidental a partir de Sócrates ou mesmo de Parmênides. ${ }^{14}$ Um processo de decadência que se assemelha a uma enfermidade verificada nas várias manifestações filosóficas, políticas e culturais do período e que se expressa de forma privilegiada, segundo Nietzsche, por meio da figura emblemática de Richard Wagner.

\section{Wagner e a modernidade como décadence}

Nos anos de 1887 e 1888, Wagner é um dos nomes mais mencionados por Nietzsche para exprimir o diagnóstico de seu tempo. Tal peculiaridade semântica do autor do Parsifal se justificaria porque "por meio de Wagner a modernidade fala sua linguagem mais íntima: [com Wagner], ela não dissimula seu bem nem o seu mau, ela perde toda a vergonha diante de si mesma". ${ }^{15}$ Outro motivo é que Wagner seria "o artista moderno por excelência, o Cagliostro da modernidade", ${ }^{16}$

12. Fragmento de 1885-1886 2[165] / NIETZSCHE, 1988, vol. 12, p. 147. Conferir também a seção três do prefácio de Aurora. Essa questão foi analisada por nós no artigo: PASCHOAL, A. E. Nietzsche, Kant e a filosofia como sedução moral. In: Kant e-Prints, Campinas, v. 4, n. 2, 2009, p. 333.

13. GM II 11 / NIETZSCHE, 1988, vol. 5, p. 310. Apresentamos alguns aspectos do debate de Nietzsche com Dühring em: PASCHOAL, A. E. Nietzsche e Dühring: ressentimento, vingança e justiça. In Revista Dissertatio, Pelotas, n. 33, inverno de 2011, p. 147-172.

14. Conferir, respectivamente, sobre Sócrates: NT 12 e 13 / NIETZSCHE, 1988, vol. 1, p. 75-88 e sobre Parmênides: FTG 9 / NIETZSCHE, 1988, vol. 1, p. 833-839.

15. WA, Prefácio / NIETZSCHE, 1988, vol. 6, p. 12. Não cabe aqui uma análise da relação de amizade e afastamento de Nietzsche em relação a Wagner. Sobre o tema, em língua portuguesa, sugiro a leitura do livro de Iracema Macedo intitulado: Nietzsche, Wagner e a época trágica dos gregos. (São Paulo: Annablume, 2006).

16. WA 5 / NIETZSCHE, 1988, vol. 6, p. 23. Figura curiosa do século XVIII, o Conde de Cagliostro, reconhecido por muitos como um místico, não passaria de um charlatão envolvido na realização de diversos delitos. 
exercendo um misterioso poder de sedução, capaz de obrigar quem se encontra ao seu redor a "ser wagneriano", ${ }^{17}$ leia-se, a corresponder àquela concepção de moderno representada por ele.

Wagner seria, assim, uma "poderosa lente de aumento" cuja finalidade seria "tornar visível um estado de miséria geral, porém, dissimulado, pouco perceptível".$^{18} \mathrm{Ou}$, mais ainda, como um caso exemplar, ele tornar-se-ia elucidativo para a compreensão daquele estado de miséria geral, designado por meio da expressão "décadence" ${ }^{19}$

O termo "décadence", utilizado por Nietzsche em associação com o nome de Richard Wagner para designar a modernidade, foi retirado das Essais de psychologie contemporaine, de Paul Bourget. ${ }^{20}$ Com uma configuração peculiar, pode-se dizer que a décadence se diferencia da ideia geral de decadência, desagregação e dissolução, entendida apenas como o declínio e fechamento de um ciclo vital. Antes, o termo décadence é utilizado por Nietzsche para nomear uma forma especial de decadência, que deixa de ser um declínio após um período de expansão, para se tornar - enquanto desagregação, declínio - o modo de ser próprio de uma determinada configuração de forças. Numa palavra, um modo de ser adoentado.

Particularmente, o termo é utilizado para fazer menção àquele processo decadencial que tem lugar na cultura ocidental a partir de Sócrates, desdobrando-se com o Cristianismo e encontrando sua conformação mais acentuada na modernidade, por exemplo, na música de Wagner. Contudo, a despeito do uso do termo em associação a Wagner, Nietzsche o utiliza também em relação a si mesmo, por exemplo, quando afirma: "descontando mesmo que eu sou um décadent,

17. WA, Prefácio / NIETZSCHE, 1988, vol. 6, p. 12.

18. EH, Por que sou tão sábio, 7 / NIETZSCHE, 1988, vol. 6, p. 274.

19. WA, Prefácio / NIETZSCHE, 1988, vol. 6, p. 11.

20. BOURGET, P. Essais de psychologie contemporaine. Paris: Gallimard, 1993. A leitura de Paul Bourget, contudo, é anterior a essa data, 1888. O autor foi mencionado por Nietzsche em anotações pessoais já no inverno de 1883 1884 (Fragmento de 1883-1884 24[6]/ NIETZSCHE, 1988, vol. 10, p.646). Para mais informações sobre a apropriação do conceito por Nietzsche a partir dos escritos de Paul Bourget, sugiro, em português: OLIVERIRA, JELSON R. Bourget fonte de Nietzsche: o conceito de décadence para a exumação de um século. In: PASCHOAL, A. E.; FREZZATTI JR., W. A. 120 anos de Para a genealogia da moral. Ijuí: Editora UNIJUÍ, 2008, p. 107-127. 
sou também o seu contrário". ${ }^{21}$ Tal uso do termo, ao certo ambíguo, abre um importante viés para a interpretação da relação de Nietzsche com a modernidade, pois se ele é um décadent, visto ser também um filho de seu tempo, "assim como Wagner", ele é ao mesmo tempo diferente de Wagner, pois teria "compreendido isso [a décadence, seu tempo]" e se "defendido"22 dela. Ao pontuar sua peculiaridade em relação a outros décadents, como Wagner, e ao apresentar-se como um "décadent recalcitrante" ou de um "décadent com má consciência", ${ }_{1}^{23}$ Nietzsche estaria então indicando a possibilidade de se extrair diferentes consequências de seu tempo, do legado oferecido pela modernidade.

Retomando, por ora, a ideia de décadence apenas em sua correlação com Wagner, vale notar que ela não diz respeito somente à obra artística do músico. A proficuidade semiótica de Wagner vai além do campo artístico, pois, também sob outros aspectos, como é o caso da fisiologia e da medicina, ele seria um "caso muito interessante", "completo" e, portanto, ilustrativo. Nesse sentido, Nietzsche menciona, por exemplo, "o caráter convulsivo de seus afetos [de Wagner], sua sensibilidade superexcitada, seu paladar, que sempre anseia por temperos cada vez mais picantes, sua instabilidade, que ele disfarça como princípios e, não menos importante, a escolha de seus heróis e heroínas, considerados como tipos psicológicos (- uma galeria de doentes! - )". ${ }^{24} \mathrm{Ou}$ seja, Wagner, como uma "nevrose", exprimiria outro traço básico da modernidade, seu adoecimento crônico, visto que nada seria "mais moderno do que esse adoecimento em todos os sentidos, esse espasmo e sobre-excitação da maquinaria nervosa". ${ }^{25}$

Tendo em vista ainda a modernidade criticada por Nietzsche, esse adoecimento pode ser verificado de forma peculiar no campo dos valores. Um campo cujas incoerências também são evidenciadas por meio da figura de Wagner, apontado por Nietzsche como o mestre de uma falsidade semelhante àquela da moral de rebanho, que opera uma inversão dos valores da moral nobre, além de enfear "o valor das coi-

21. EH, Por que sou tão sábio, 2 / NIETZSCHE, 1988, vol. 6, p. 266.

22. WA, Prefácio / NIETZSCHE, 1988, vol. 6, p. 11.

23. Fragmento de 1888 15[88] / NIETZSCHE, 1988, vol. 13, p. 458 - grifo nosso. Conferir à respeito: BORCHMEIER, D. Décadence. In: Niemayer, Ch. (Org.) Nietzsche-Lexikon. Darmstadt: WBG, 2009.

24. WA 5 / NIETZSCHE, 1988, vol. 6, p. 22.

25. WA 5 / NIETZSCHE, 1988, vol. 6, p. 23. 
sas, nega[r] o mundo" e anunciar o "evangelho dos humildes". Para Nietzsche, a "boa consciência' na mentira, que identifica em Wagner, é algo moderno por excelência" ao ponto de "quase se definir a modernidade por meio dela" ${ }^{26}$ Assim, para além da falta de harmonia e de estilo de sua música e de suas características fisiológicas, Wagner seria também a expressão dos traços modernos da vitória plebeia na moral, que antes de qualquer coisa significa a produção de ideais por meio de uma falsificação de valores.

Por fim, um último campo no qual se verifica os traços característicos da décadence é na "alma". Também nesse campo é possível falar de uma espécie de "[des]ordem", associada à falta de "paz" e de "sossego" e, consequentemente, à ausência de "etiqueta", ${ }^{27}$ de respeito por um ordenamento mínimo de valores. Em especial nesse campo, tal desordem implica uma confusão entre meios e fins, entre aquilo que deve ser colocado acima e o que deve ficar abaixo, por exemplo, entre a disposição para comandar e legislar, por um lado, e os sentimentos de vingança e de "inimizade", por outro. ${ }^{28}$ Contudo, se legislar deveria ter primazia na alma daqueles que tem o dever de comandar, como é o caso do filósofo, o que Nietzsche observa na modernidade, como o produto do trabalho filosófico, é uma erudição oca e um labor conceitual e crítico no lugar da reflexão sobre o valor dos valores "sobre a vida e o valor da vida" ${ }^{29}$ Como se, perturbado pelo barulho dos "órgãos serviçais", ou encantado por esse burburinho, o filósofo deixasse de se ocupar do que é mais importante: o "reger, prever, predeterminar". ${ }^{30}$

26. WA, Epílogo / NIETZSCHE, 1988, vol. 6, p. 52. Grifo nosso.

27. GM II 1 / NIETZSCHE, 1988, vol. 5, p. 292.

28. Tal confusão, que é frequentemente designada por Nietsche por meio do termo "caos" (WA 7/ NIETZSCHE, 1988, vol. 6, p. 24), tem relação direta com o modo como o homem se relaciona com seu passado, que não é assimilado por ele, mas torna-se um peso que o impede de acessar seu "o verdadeiro Si-Próprio" (GIACOIA JR, O. Nietzsche x Kant. Rio de Janeiro: Casa da Palavra / São Paulo: Casa do Saber, 2012, p. 234), de conferir ao seu estilo uma unidade.

29. ABM 205 / NIETZSCHE, 1988, vol. 5, p. 132.

30. GM II 1/ NIETZSCHE, 1988, vol. 5, p. 291. 


\section{A precedência (Rangordnung)}

Conforme vimos, para além daquele caráter polissêmico, apontado inicialmente, é possível identificar traços comuns associados ao termo "modernidade" que são explicitados por meio do conceito de décadence e da figura de Richard Wagner. Interessa neste momento identificar, tendo em vista a própria demarcação feita do conceito, o que poderia ser chamado de uma disposição contrária à décadence nos escritos de Nietzsche, que deve, igualmente, recobrir o campo da cultura, da moral e dos valores. Essa disposição contrária, grosso modo, pode ser designada pelo termo "precedência", "hierarquia", ou, simplesmente, "Rangordnung". ${ }^{31}$ Sem perder de vista que, neste caso, o tipo psicológico a ser tomado como uma semiótica seria o próprio Nietzsche ou, como nos interessa neste momento, o caso Nietzsche. ${ }^{32}$

Nietzsche opõe a Rangordnung, especialmente em Além de Bem e Mal, a uma sociedade que, segundo ele, teria colocado de "cabeça para

31. Conquanto o termo "Rangordnung" seja convencionalmente traduzido por "hierarquia", optamos, neste artigo, em traduzi-lo por "precedência" ou deixar o termo original. O motivo desta opção é que existe, para o termo "hierarquia", um correlato na língua alemã que normalmente não é utilizado por Nietzsche. Trata-se do termo "Hierarcbie" que, embora possa ser à grosso modo tomado como sinônimo de "Rangordnung", e embora, em alguns casos isolados, o próprio Nietzsche não pareça ocupado em diferenciá-los, possui uma conotação diferente do termo "Rangordnung", colocando em relevo um ordenamento que inclui um comando das partes localizadas acima, sobre as demais. Como se tem, por exemplo, numa hierarquia militar. Para nós, contudo, como se pode observar no decorrer do artigo, o importante é acentuar a diferença entre os termos "décadence", entendido como um caos, e "Rangordnung", ou "precedência", entendido não tanto como uma hierarquia de comando, mas como um ordenamento das partes, além da primazia que algumas partes devem ter sobre as demais.

32. A expressão "O caso Nietzsche" não é nossa. Ela é formulada por Carl Fuchs em um escrito contra Wagner, que Nietzsche menciona em uma carta de 27 de dezembro de 1888. (NIETZSCHE, F. Sämtliche Briefe. Kritische Studienausgabe (KSB) in 8 Bänden. Herausgegeben von Giorgio Colli und Mazzino Montinari. Berlin/New York: Walter de Gruyter, 1986, vol.8, p. 555). Contudo, o sentido que conferimos ao termo é peculiar, na medida em que interpretamos o personagem Nietzsche, veiculado pelo filósofo em seu texto, como um contraponto a Wagner, que também pode ser considerado ali como um personagem, um tipo ou, mais propriamente, como um caso exemplar. 
baixo todas as valorações" para dar "consolo aos sofredores" e convertido o "todo o amor às coisas terrenas e ao domínio sobre a terra em ódio à terra e ao que é terreno". ${ }^{33}$ Opõe-na também ao "caos" de modos de vida e de cultura que compromete os instintos das "almas modernas $^{\prime \prime 34} \mathrm{e}$, em especial, à proposição moral predominante que perde de vista as peculiaridades individuais ao pretender que aquilo "que é certo para um é certo para outro". ${ }^{35}$ Nesse sentido, em oposição àquele caos em relação aos valores, caracterizado por uma massificação que dilui as peculiaridades individuais numa massa homogênea e disforme, o que Nietzsche pretende colocar em relevo é que a própria ideia de valores implica uma disposição que não se faz em linha, mas com o respeito às precedências. O respeito pelas diferenças de "estados de ânimos" e de "problemas", ${ }^{36}$ por exemplo, a diversidade entre os homens, que se manifesta por meio dos "grupos de palavras que dentro de uma alma despertam mais rapidamente, tomam a palavra, dão ordens", ${ }^{17}$ algo que decide a ordem interna dos valores daquela alma, sua tábua de bens.

Quando se trata de um indivíduo, pode-se obter uma medida para o estabelecimento dessa precedência (Rangordnung) tendo em vista alguns critérios que permitem ressaltar sua complexidade e peculiaridades. Por exemplo, coloca-se em destaque a profundidade à qual uma "alma" pode chegar considerando-se: o "quão profundamente um homem pode sofrer", ${ }^{38}$ tendo por pressuposto que é a interiorização do sofrimento que alarga seus horizontes; o tempo necessário para um homem ser compreendido, pressupondo justamente aquela complexidade de problemas e estados de ânimos; a fé que ele tem em si mesmo, especialmente pelo reconhecimento de seu lugar em um ordenamento e pelo respeito a esse lugar, não aceitando, por exemplo, ser tomado como meio, mas apenas como fim, e, para completar, es-

\footnotetext{
33. ABM 62 / NIETZSCHE, 1988, vol. 5, p. 82.

34. ABM 224 / NIETZSCHE, 1988, vol. 5, p. 158.

35. ABM 221 / NIETZSCHE, 1988, vol. 5, p. 156.

36. ABM 213 / NIETZSCHE, 1988, vol. 5, p. 148.

37. ABM 268 / NIETZSCHE, 1988, vol. 5, p. 222.

38. ABM 270 / NIETZSCHE, 1988, vol. 5, p. 225.
} 
pecialmente no caso dos filósofos, a qualidade de seu riso, pela leveza e inocência à qual ele pode chegar, aproximando-se da criança. ${ }^{39}$

Nietzsche contrapõe ainda a crença na Rangordnung, no ordenamento oligárquico de nosso organismo e de nossos valores à desordem democrática, que tem "gosto e língua para tudo". ${ }^{40} \mathrm{O}$ mesmo caos que, nos termos de uma "décadence literária" ${ }_{1}^{41}$ significa a perda do todo pela justaposição das partes isoladas. Nesse sentido, o oposto a ela, aquilo que falta à modernidade, seria justamente um ordenamento que não perdesse de vista a precedência, a diferença de valores entre coisas diferentes e as individualidades. De forma particular, para Nietzsche, o filósofo é quem deve se ocupar com o estabelecimento desse tipo de precedência. Esse é o motivo pelo qual Nietzsche se dirige a eles de forma ríspida, reconhecendo o trabalho de seus contemporâneos no limite da crítica, da erudição de uma "teoria do conhecimento"42 que os afasta da obrigação de "opinar sobre a elevada questão do grau" ${ }^{1 / 3}$ e de produzir, com seus escritos, formas de comprometimento. ${ }^{44}$

39. Na seção "das três metamorfoses" de seu Zaratustra, Nietzsche mostra a precedência que a forma da criança, da inocência, do riso e do esquecimento possui em relação às demais formas, a do leão e a do camelo.

40. ABM 224 / NIETZSCHE, 1988, vol. 5, p. 158.

41. WA 7 / NIETZSCHE, 1988, vol. 6, p. 27.

42. ABM 204 / NIETZSCHE, 1988, vol. 5, p. 131. Entre aspas, no texto de Nietzsche, "Erkenntnisstheorie", entendida como aquela prática, que mencionamos anteriormente, de "estabelecer e colocar em fórmulas" os corpos de valorações que se tornaram dominantes e são apresentados como "verdades" (ABM 211). Ou "como um tímido epoquismo e doutrina da abstenção" ("als eine schüchterne Epochistik und Enthaltsamkeitslehre").

43. ABM 204 / NIETZSCHE, 1988, vol. 5, p. 129. Nesse aforismo, Nietzsche utiliza o termo "Rang", precisamente o radical da palavra "Rangordnung", que traduzimos por precedência ou, a rigor, grau numa classificação.

44. Na seção 7 do capítulo "Por que sou tão sábio", de Ecce Homo, o caso Nietzsche oferece novamente um exemplo no sentido contrário do que ele critica nos filósofos de seu tempo, ao afirmar "nunca dei um passo em público que não me comprometesse - este é o meu critério para uma ação correta". Neste caso, compromisso equivale a estar pessoalmente envolvido com aquilo que escreve e responder por isso, num sentido em que um exemplo ilustrativo seria a figura de Jesus ou de Sócrates, que respondem pessoalmente, com suas vidas, por suas afirmações. 
A demarcação do papel do filósofo, associada em especial à ideia de comprometimento, nos reconduz à questão de como Nietzsche se relaciona com seu tempo. A elucidação dessa questão requer uma atenção especial para sua autodesignação como um "homem moderno" e também sua afirmação de que é onde ele se acha "em perigo" que encontra sua "bem aventurança". ${ }^{45}$ Ela demanda um olhar mais atento à correlação dos conceitos de décadence e Rangordnung com os de adoecimento e saúde e também à proposição do filósofo de que, para ele, "a doença mesma pode ser um estimulante para a vida: apenas é necessário ser saudável o suficiente para esse estimulante!". ${ }^{46}$ Em resumo, ela exige uma atenção ao conceito de doença em Nietzsche e, em especial, para o caráter paradoxal desse conceito, privilegiado pelo autor na explicitação de sua ideia de modernidade e do modo como se relaciona com ela.

\section{Da utilidade da doença para a vida}

Os termos saúde e doença possuem contornos peculiares na filosofia de Nietzsche. Eles não remetem, por exemplo, a uma espécie de estabilidade física e/ou mental, por um lado, e a um quadro de extenuação, por outro. Na realidade, não é tarefa fácil, do ponto de vista fisiológico, estabelecer uma diferença entre saúde e doença, pois, para o filósofo "uma saúde em si não existe". ${ }^{47}$

Assim, deixando de lado "o conceito de uma saúde normal, juntamente com uma dieta normal e curso normal da doença" ${ }^{48}$ Nietzsche considera os conceitos de saúde e doença a partir de características e condições individuais, como se verifica no caso das virtudes. Nesse sentido, ele recorre a uma afirmação de Ariston de Quios ${ }^{49}$ de que "a virtude é a saúde da alma", enfatizando o caráter pessoal ao acrescentar nela o pronome possessivo "tua": "a tua virtude é a saúde da tua

45. ABM 224 / NIETZSCHE, 1988, vol. 5, p. 160.

46. WA 5 / NIETZSCHE, 1988, vol. 6, p. 22.

47. GC 120 / NIETZSCHE, 1988, vol. 3, p. 477.

48. GC, 120 / NIETZSCHE, 1988, vol. 3, p. 477.

49. Ariston de Quios, que viveu aproximadamente entre 320-250 a. C., era um filósofo estoico, discípulo de Zenão de Cítio, que confere grande importância ao saber moral e à investigação acerca da distinção entre virtude e vício, o conhecimento de que fato interessa para o sábio em sua busca do bem. 
alma" ${ }^{50}$ Recorde-se, neste ponto, que a noção de virtude utilizada por Ariston de Quios é a de Aristóteles, que no livro dois da Ética a Nicômaco acentua o caráter pessoal da virtude, cuja medida deve ser tomada pela pessoa e não pelo objeto. Nesse caso, o meio termo não corresponderia, segundo o Filósofo, à simples divisão em duas partes iguais, sendo, antes, uma medida estabelecida tendo em vista o indivíduo particular, do mesmo modo como um treinador precisa respeitar os diferentes níveis em que cada atleta se encontra ao prescrever os alimentos para eles. ${ }^{51}$

A compreensão de como o processo saúde-doença é utilizado por Nietzsche deve tomar ainda por pressuposto que, para ele, "não se deve derivar entidades ou princípios distintos, do fato de um organismo vivo estar em luta consigo e se tornar um campo de batalha". ${ }^{52}$ Da mesma forma, não se pode perder de vista que, para ele, a própria tensão produzida nesse processo é o dístico de uma "natureza elevada" e vincula-se à possibilidade de crescimento da "planta 'homem" ${ }^{\prime \prime}{ }^{54}$

A partir de tais pressupostos, não se sustenta a hipótese de que Nietzsche estaria interessado apenas em superar debilidades e sofrimentos rumo a uma condição ou um estado perfeitamente saudável, como se ele estivesse simplesmente interessado em descobrir medicamentos e técnicas de um cuidado de si, visando atingir uma saúde ideal ou uma pacificação aos moldes daquela desejada pelo homem do rebanho. Antes, a compreensão da analogia estabelecida entre Nietzsche e suas debilidades, algumas genéticas e outras resultantes de certos nutrientes de difícil digestão que ele absorvera na juventude, como a filosofia de Schopenhauer e a arte de Wagner, deve seguir por outra linha de raciocínio, que compreende duas questões e uma premissa. A primeira questão diz respeito ao próprio filósofo, a saber, se ele poderia "prescindir da doença, até mesmo para [sua] virtude, e se [sua] avidez de conhecimento e autoconhecimento não necessitaria tanto

50. GC 120 / NIETZSCHE, 1988, vol. 3, p. 477. Grifo nosso.

51. Ética II, 1106b. Cf. também I 1097a, quando o Filósofo afirma que o médico não estuda a saúde de um ponto de vista geral, mas do ponto de vista do indivíduo, "pois é ao indivíduo que ele cura".

52. Fragmento de 1888 14[65] / NIETZSCHE, 1988, vol. 13, p. 250.

53. GM I 16 / NIETZSCHE, 1988, vol. 5, p. 286.

54. ABM 44 / NIETZSCHE, 1988, vol. 5, p. 61. 
da alma doente quanto da alma sadia" ${ }^{55}$ A segunda questão diz respeito ao produto do conhecimento filosófico: o "que virá a ser do pensamento mesmo que é submetido à pressão da doença?" ${ }^{56} \mathrm{~A}$ premissa que articula as duas questões é: "apenas a grande dor, essa dor lenta e prolongada, a que não tem pressa, na qual somos queimados como que madeira verde, força a nós filósofos a atingir a nossa profundidade extrema...". ${ }^{57}$

Tendo em vista, pois, o caso Nietzsche, o que se coloca diante dos olhos do leitor é o exemplo de um pensamento submetido à pressão da doença. Conforme se deduz a partir de afirmações feitas por ele sobre os elementos presentes na produção de Aurora: uma "espiritualização quase inseparável de uma extrema pobreza em sangue e músculo", bem como a dor e a fraqueza fisiológica ${ }^{58}$. Esse tipo de vivência, incluindo a passagem por períodos de severas enfermidades, que teria exigido dele a resistência a uma longa pressão, teria também possibilitado a ele tomar como um problema "a saúde em geral do povo, tempo, raça e humanidade" ${ }^{59} \mathrm{Ou}$ seja, a sua experiência pessoal com a décadence, o fato de ele ser experimentado justamente em questões de décadence, teria um papel central no desenvolvimento daquele olhar de psicólogo que o capacitaria para fazer seu peculiar "diagnóstico da alma moderna". 60

Tal modo de conceber a relação de Nietzsche com sua enfermidade explica a sua gratidão para com Wagner e também para com a modernidade. Tal "acaso feliz" ${ }^{\prime \prime 1}$ permitiu a ele desenvolver a capacidade de ver além do ângulo e desvendar valores que são opostos a ele mesmo. Ou seja, "da ótica do doente ver conceitos e valores mais sãos e, inversamente, da plenitude e certeza da vida rica descer os olhos ao secreto lavor do instinto de décadence". Essa capacidade de ver de outro ângulo é apontada por Nietzsche como sua maestria. Se ele é "mestre"

55. GC 120 / NIETZSCHE, 1988, vol. 3, p. 477.

56. GC, Prólogo, 2 /NIETZSCHE, 1988, p. 347.

57. GC, Prólogo, 3 / NIETZSCHE, 1988, vol. 3, p. 350.

58. EH, Porque sou tão sábio, 1 / NIETZSCHE, 1988, vol. 6, p. 265. Os apontamentos de Aurora são de 1880 e a publicação de junho de 1881, período em que o filósofo de fato intercala adoecimento e convalescença.

59. GC, Prefácio, 2 / NIETZSCHE, 1988, vol. 3, p. 349.

60. WA, Epílogo / NIETZSCHE, 1988, vol. 6, p. 53.

61. WA, Epílogo / NIETZSCHE, 1988, vol. 6, p. 53. 
em algo, se ele pôde retirar algum benefício de seu "mais longo exercício, [de sua] verdadeira experiência", esse seria justamente o fato de ele possuir "mão bastante para deslocar perspectivas". ${ }^{62}$ Em resumo, aquelas vivências e o modo como elas são exploradas por Nietzsche tornaram-se, segundo sua convicção, a condição de possibilidade para o aparecimento do aspecto mais importante de sua filosofia.

O caso Nietzsche exemplificaria, assim, uma relação saudável do homem com suas vivências, com seu passado. Uma relação saudável com o passado não pode ser dominada pela tentativa de esquecimento das vivências passadas como se elas não tivessem acontecido. Também não pode ser marcada por sentimentos de rancor, sede de vingança e ressentimento, revelando um passado não digerido que obstrui o presente. Saudável, nesse caso, é "tomar a si mesmo como um fato, não se querer 'diferente" ${ }^{\prime \prime \prime} .{ }^{63}$ Dessa forma, o passado não é um peso ${ }^{64}$ mas o registro de uma pré-história (mesmo que repleta de adoecimentos) que estabelece as condições de possibilidade do presente. O passado liga-se, assim, de modo indissociável ao presente, na medida em que o homem não apresente a insensatez de "querer para trás" ${ }^{65}$ Em outros termos, uma vida saudável, assim como o esclarecimento sobre si mesmo dependem da vitória - a cada instante - sobre o ressentimento, sobre a sede de vingança.

Neste ponto, é possível observar a relação do homem com o seu passado a partir de um curioso movimento circular que pode se fazer em dois sentidos. Num deles tem-se o eterno retorno dos sentimentos ruins produzidos pela sede de vingança obliterando a vida presente e, no outro, o eterno retorno das vivências como aceitação incondicional daquele passado. Ao certo, o ordenamento esperado, nesse caso, segue a disposição das coisas no tempo: o presente é tornado possível em função do passado. A passagem do homem pela sua história deixa nele marcas indeléveis em sua pele, órgãos e alma que são tanto inalteráveis

62. EH. Porque sou tão sábio, 1 / NIETZSCHE, 1988, vol. 6, p. 266.

63. EH, Por que sou tão sábio, 6/ NIETZSCHE, 1988, vol. 6, p. 273.

64. Sobre a noção de peso, considero salutar a leitura do livro: RUBIRA, L. Nietzsche: do eterno retorno do mesmo à transvaloração de todos os valores. São Paulo: Discurso Editorial: Barcelona, 2010., em especial a argumentação que se desenvolve no capítulo "O eterno retorno do mesmo: o 'novo peso"'.

65. GIACOIA JR., O. Nietzsche x Kant, p. 233. 
quanto indispensáveis na medida em que constituem o solo sobre o qual ele pode construir seu presente e idealizar seu futuro.

De fato, as experiências passadas podem produzir efeitos diversos em diferentes indivíduos, dependendo da proporção em que cada um é "saudável o suficiente para o estimulante" ${ }^{66}$ Contudo, é fato que os efeitos produzidos dependem também das peculiaridades medicamentosas do estimulante. Assim, considerando de forma peculiar a modernidade como esse estimulante, Nietzsche faz um interessante registro em uma anotação pessoal do outono de 1887 :

O problema do século XIX. Se o seu lado forte e o seu lado fraco estão interligados? Se ambos seriam talhados de uma única madeira? Se a diversidade de seus ideais, cujas contradições são alçadas a um ponto elevado, serviria a algo elevado? - Pois, isto poderia ser a predisposição para a grandeza e, nessa medida, crescer numa tensão mais forte. A insatisfação, o niilismo poderia ser um bom sinal. ${ }^{67}$

Nesse sentido, vale observar como uma característica do estimulante em questão, a modernidade, pode ter possibilitado um aumento peculiar da força inventiva do homem, na medida em que elevou a tensão capaz projetá-lo para novos horizontes. Em especial, segundo Nietzsche, na modernidade "a luta contra Platão, ou (...) a luta contra a pressão cristã-eclesiástica de milênios (...) produziu na Europa uma magnífica tensão do espírito, como não houve na terra até então [e] com um arco assim tenso é possível a partir de agora mirar em alvos ainda mais distantes" ${ }^{\prime 68}$ Tal característica, de tensão, sofrimento e possibilidades constitui, ao certo, o legado que Nietzsche tem em mente quando se apresenta como herdeiro da modernidade e se dispõe a levá-la adiante, até suas últimas consequências. Ela pode, inclusive, ser tomada como medida para o conceito de grande-saúde:

Aquele cuja alma anseia haver vivenciado todo o perímetro dos valores e desejos até hoje existentes e haver navegado todas as costas desse "Mediterrâneo" ideal, quem quer, mediante as aventuras

66. WA 5 / NIETZSCHE, 1988, vol. 6, p. 22.

67. Fragmento de 1887, 9[186] / NIETZSCHE, 1988, vol. 12, p. 449-450. Neste ponto, Nietzsche se diferencia dos "metafísicos de todos os tempos", que não admitem, segundo o ele, que algo elevado pode nascer de seu oposto (NIETZSCHE, 1988, vol. 5, p. 16-17).

68. ABM, Prólogo / NIETZSCHE, 1988, vol. 5, p. 12-13. 
das próprias experiências, saber como se sente um descobridor e conquistador do ideal, e também um artista, um santo, um legislador, um sábio, um erudito, um devoto, um adivinho, um divino excêntrico de outrora: ele necessita para isso mais e antes de tudo uma coisa: a grande saúde - uma tal que não apenas se tem, mas constantemente se adquire e é preciso adquirir, pois sempre de novo se abandona e é preciso abandonar... ${ }^{69}$

\section{Um passo adiante na décadence}

Está claro que é o próprio Nietzsche que afirma que o seu projeto consiste em seguir "passo a passo adiante na décadence" e que é, também ele, que entende a modernidade como um legado a ser levado adiante, tomando-a mesmo como um estimulante. Tudo isso, porém, não o coloca numa linha de continuidade com os propósitos da modernidade. De fato, Nietzsche nunca deixou de compreender a cultura de sua época como sintoma de adoecimento e niilismo. Ele nunca perdeu de vista que tal cultura teria estabelecido por meta tornar o "homem" um "animal manso e civilizado, um animal doméstico", lançando mão, para isso, dos instintos de "reação e ressentimento". ${ }^{71}$

Ser herdeiro, portanto, não significa perder o distanciamento crítico em relação àquele empreendimento que foi vencedor no mundo ocidental, traduzido pela fórmula "moral de rebanho". Não significa também pontuar uma diferença em relação a outros herdeiros daquela grande tensão, que não pretendem ultrapassar os limites da modernidade, pois, eles sentem aquela tensão "como uma miséria" e se associam às tentativas de "distender o arco", como se fez "uma vez por meio do jesuitismo e uma segunda vez por meio do esclarecimento democrático $(\ldots)^{\prime \prime} .^{72}$

Nesse sentido, como lembra Urs Marti, referindo-se especialmente à Revolução Francesa, ainda que seja plausível afirmar que Nietzsche constrói sua filosofia a partir da modernidade e mesmo do que poderia ser chamado de um "projeto de esclarecimento", o fato é

69. GC 382 / NIETZSCHE, 1988, vol. 3, p. 636.

70. CI, Incursões de um extemporâneo, 43 / NIETZSCHE, 1988, vol. 6, p. 144.

71. GM I 11 / NIETZSCHE, 1988, vol. 5, p. 276.

72. ABM, Prefácio / NIETZSCHE, 1988, vol. 5, p. 13. 
que ele não propõe qualquer "reabilitação da revolução". ${ }^{73}$ A pretensão de reeditar antigas convicções, segundo Nietzsche, é algo próprio dos sacerdotes e moralistas, que tentam sem sucesso "levar a humanidade a uma medida anterior de virtude, 'aparafusá-la de volta"' ${ }^{74}$

A pertença de Nietzsche à modernidade não deixa ainda de pontuar sua diferença (do caso Nietzsche) em relação aos "filósofos da moda" e também aos críticos e céticos. A diferença consiste na impossibilidade deles ultrapassarem os limites demarcados pela definição de "trabalhadores filosóficos". Ou seja, eles não apresentam a "segurança da medida de valor"75 como o método que permitiria colocar o valor dos valores de seu tempo em questão e, também, tomar a si mesmos como experimento ${ }^{76} \mathrm{e}$, assim, longe de uma erudição vazia, chegar a um conhecimento que "nem os mais sábios nem os mais inteligentes podem saber" ${ }^{\prime \prime}{ }^{77}$ Eles não podem chegar àquele saber diferenciado pela experiência da "grande dor", que é tomado, no caso de Nietzsche, como o "extremo libertador do espírito" ${ }^{78}$ Um saber que, veiculando, por um lado, a experiência, entendida como uma vivência (Erlebniss), e, por outro, o fato de se permitir experimentar algo (Experiment / Erfabrung), corresponde à passagem pelo padecimento, o ter "a vida é um meio de conbecimento". ${ }^{79}$

Em oposição, portanto, ao caso Wagner, o caso Nietzsche é um décadent, mas é também o seu contrário, ele apresenta os traços de um tipo que transforma o estar enfermo num "um enérgico estimulante ao viver, ao mais-viver ${ }^{\prime \prime 80}$ e que delineia o fazer filosófico como uma in-

73. MARTI, U. Nietzsche kritik der Französischen Revolution. In: NietzscheStudien, Berlin, n. 19, 1990, p. 316.

74. CI, Incursões de um extemporâneo, 43 / NIETZSCHE, 1988, vol. 6, p. 144.

75. ABM 210 / NIETZSCHE,1988, vol. 5, p. 143.

76. A noção de experimento é provavelmente utilizada por Nietzsche sob a influência de Ralph Waldo Emerson (OTTMANN, H. Nietzsche Handbuch. Stuttgart / Weimar: Metzler, 2000, p. 230).

77. ABM 270 / NIETZSCHE, 1988, vol. 5, p. 225. Trata-se, segundo Nietzsche, da "arrepiante certeza da qual é impregnado e tingido [esse homem do profundo sofrimento], de graças a seu sofrimento saber mais do que podem saber os mais inteligentes e os mais sábios..."

78. GC Prólogo, 3 / NIETZSCHE, 1988, vol. 3, p. 350.

79. GC 324 / NIETZSCHE, 1988, vol. 3, p. 553.

80. EH, Por que sou tão sábio, 2 / NIETZSCHE, 1988, vol. 6, p. 266. 
cursão em seu tempo feita por um extemporâneo. Somente assim ele pode estar em seu tempo sem que isso implique uma subsunção aos valores e projetos tanto uníssonos quanto sem estilo da sociedade burguesa.

\section{Referências Bibliográficas:}

ARISTÓTELES. Ética a Nicômaco. Trad. de Leonel Vallandro e Gerd Bornheim. São Paulo: Abril Cultural, 1971.

BORCHMEIER, D. Décadence. In: Niemayer, Ch. (Org.) NietzscheLexikon. Darmstadt: WBG, 2009.

BOURGET, P. Essais de psychologie contemporaine. Paris: Gallimard, 1993.

GIACOIA JR. O. Esclarecimento (per) verso: Nietzsche à sombra da ilustração. In: Revista de Filosofia Aurora, v. 20, n. 27, pp. 243-259, Curitiba, Champagnat, jul./dez. 2008.

Moralidade e Memória: Dramas do Destino da Alma. In: PASCHOAL, A. E. \& FREZZATTI JR., W. A. (Orgs.) 120 Anos de Para a Genealogia da Moral. Ijuí: Ed. Unijuí, pp. 187-241, 2008.

Nietzsche x Kant. Rio de Janeiro: Casa da Palavra / São Paulo: Casa do Saber, 2012.

KUHN, E. Cultur Civilisation, die Zweideutigkeit des 'Modernen'. In: Nietzsche-Studien, n. 18, pp. 600-626, 1989.

MACEDO, I. Nietzsche, Wagner e a época trágica dos gregos. São Paulo: Annablume, 2006.

MARTI, U. Nietzsche kritik der Französischen Revolution. In: NietzscheStudien, n. 19, pp. 312-335, 1990.

NIETZSCHE, F. Sämtlilche Werke. Kritische Studienausgabe (KSA) in 15 Einzelbänden. Herausgegeben von Giorgio Colli und Mazzino Montinari. Berlin/New York: Walter de Gruyter, 1988.

Sämtliche Briefe. Kritische Studienausgabe (KSB) in 8 Bänden. Herausgegeben von Giorgio Colli und Mazzino Montinari. Berlin/ New York: Walter de Gruyter, 1986.

OLIVERIRA, J. R. Bourget fonte de Nietzsche: o conceito de décadence para a exumação de um século. In: PASCHOAL, A. E. FREZZATTI JR., W. A. 120 anos de Para a genealogia da moral. Ijuí: Editora UNIJUÍ, 2008, pp. 107-127.

OTTMANN, H. Nietzsche Handbuch. Stuttgart / Weimar: Metzler, 2000.

PASCHOAL, A. E. Nietzsche, Kant e a filosofia como sedução moral. In: Kant e-Prints, v. 4, n. 2, pp. 323-340, Campinas, 2009. 
Entre a décadence $e$ a rangordnung: anotações sobre a crítica de Nietzsche...

Da polissemia dos conceitos "ressentimento" e "má consciência". In: Revista de Filosofia Aurora, v. 23, n. 32, pp. 201-221, Curitiba: Champagnat, jan./jun. 2011.

Nietzsche e Dühring: ressentimento, vingança e justiça. In Revista Dissertatio 33: 147-172, Pelotas: UFPEL, inverno de 2011.

RUBIRA, L. Nietzsche: do eterno retorno do mesmo à transvaloração de todos os valores. São Paulo: Discurso Editorial: Barcelona, 2010.

SIEMENS, H. \& VAN TONGEREN, P. Introdução: o dicionário Nietzsche. In: Cadernos Nietzsche, n. 31, v. 02, pp. 31-53, São Paulo: UNIFESP, 2012. 